\title{
Haemophilus influenzae and the lung (Haemophilus and the lung)
}

Paul King

\begin{abstract}
Haemophilus influenzae is present as a commensal organism in the nasopharynx of most healthy adults from where it can spread to cause both systemic and respiratory tract infection. This bacterium is divided into typeable forms (such as type b) or nontypeable forms based on the presence or absence of a tough polysaccharide capsule. Respiratory disease is predominantly caused by the nontypeable forms (NTHi). Haemophilus influenzae has evolved a number of strategies to evade the host defense including the ability to invade into local tissue. Pathogenic properties of this bacterium as well as defects in host defense may result in the spread of this bacterium from the upper airway to the bronchi of the lung. This can result in airway inflammation and colonization particularly in chronic obstructive pulmonary disease. Treatment of respiratory tract infection with Haemophilus influenzae is often only partially successful with ongoing infection and inflammation. Improvement in patient outcome will be dependent on a better understanding of the pathogenesis and host immune response to this bacterium.
\end{abstract}

\section{Review}

Haemophilus influenzae was first identified by Pfeiffer in 1892, who (incorrectly) believed it was the cause of influenza [1]. It is an exclusively human pathogen and was the first bacterium to have its genome completely sequenced. This served as a precursor to the sequencing of the human genome.

$H$. influenzae is a component of the normal upper respiratory tract flora and is well recognized to be an important cause of systemic infection. It is also a major cause of a variety of respiratory conditions and has had a relatively low profile in this respect in comparison to some other pathogens; such as Mycobacterium tuberculosis and Streptococcus pneumoniae.

Recently there has been increasing recognition that this bacterium has a role in chronic lower respiratory tract inflammation. However the interaction between $H$. influenzae and the lung is still not well defined. A combination of bacterial pathogenic features and deficiency of host defense may permit this bacterium to establish infection in the lower respiratory tract resulting in

Correspondence: paul.king@monash.edu

Department of Respiratory and Sleep Medicine and Department of Medicine, Monash University, Monash Medical Centre, 246 Clayton Rd, Clayton, Melbourne 3168, Australia inflammation and clinical disease. This review will discuss the role of $H$. influenzae in the lower respiratory tract in particular its role in bronchitis.

\section{Microbiology}

Haemophilus influenzae is a gram-negative coccobacillus with a variable shape (pleomorphic). It grows both aerobically and anaerobically. Aerobic growth requires the presence of $\mathrm{X}$ (hemin) and $\mathrm{V}$ (nicotinamide adenine dinucleotide (NAD)) factors. In the laboratory it is classically grown on chocolate agar (Figure 1).

Haemophilus influenzae is divided into typeable and nontypeable strains on the presence or absence of a polysaccharide capsule. The typeable strains which have this capsule are classified into six serotypes (designated a to $f$ ) based on their ability to react with antisera against recognized polysaccharide capsules [2,3]. The type $\mathrm{b}$ form of $H$. influenzae (designated as Hib) is the most prominent typeable form and its capsule is composed of a linear ribosyl and ribotol phosphage polymer.

Nonencapulated forms are designated as nontypeable Haemophilus influenzae (NTHi). The NTHi strains are heterogeneous with a large number of different subtypes [4] that can be demonstrated on electrophoresis of outer membrane proteins or by enzymatic analysis. The NTHi strains are the main cause of Haemophilus respiratory

\section{Springer}




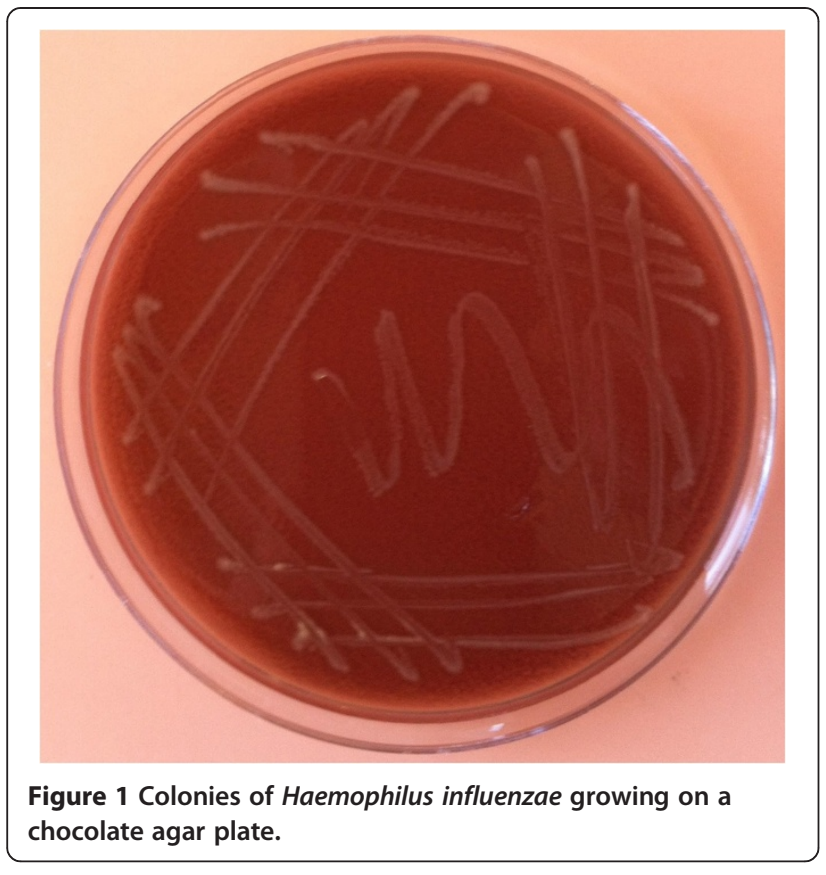

infections. NTHi is classified into biotypes using indole, urease and ornithine decarboxylase.

\section{Epidemiology}

Colonization of the upper respiratory tract with $H$. influenzae begins in infancy. Approximately $20 \%$ of infants are colonized in the first year of life and this rises progressively over time [5]. By the age of 5-6 years more than $50 \%$ of children will be colonized with this bacterium and most healthy adults (at least $75 \%$ ) will be [1]. This is a dynamic process with turnover of different strains. Children will have a strain for weeks to months, which will then be cleared and the acquisition of a new strain occurs [6]. Children will typically carry multiple strains simultaneously whilst adults will be colonized with only one strain [7].

This bacterium is spread by airborne droplets and contact with secretions [8]. Children in day centers have a particularly high incidence of infection and colonization with $H$. influenzae. The acquisition of new strains may be associated with acute exacerbations of airways disease [9]. The number of times a child is colonized with different isolates of NTHi is correlated with middle ear infection. The density of colonization is also a risk factor for the development of middle ear infection; this has been associated with lower levels of other commensal bacteria such as Streptococcus viridans [10].

The recent widespread use of the $H$. influenzae type B vaccine has caused a marked reduction in the prevalence of clinical disease arising from type b H. influenzae infection (from very common to rare). This has been associated with a proportionate decrease in the rate of nasopharyngeal colonization.

Most healthy adults will have upper airway colonization with $H$. influenzae. This process is dynamic and the predominant strains are nontypeable. The nasopharynx serves as a potential reservoir of infection from which this bacterium may spread to the lower respiratory tract.

\section{Pathogenesis}

Haemophilus influenzae strains are divided into those with a capsule (e.g. the type b form) or the nonencapsulated strains (NTHi). The encapsulated strains primarily have a role in systemic infection in conditions such as meningitis. A principal defense against systemic $H$. influenzae infection is antibody-mediated complement killing. Normal serum is bactericidal for most strains of NTHi, but naturally-occurring bactericidal activity for encapsulated bacteria is much less common, particularly in children. In contrast NTHi strains rarely cause disease outside the respiratory tract and can be considered to be primary mucosal pathogens. The vast majority of respiratory disease arises from the NTHi strains. Important pathogenic mechanisms by which $H$. influenzae establishes respiratory tract infection will now be discussed in more detail.

\section{Mucociliary interactions}

The mucociliary apparatus is a first-line structural defense against bacterial infection and $\mathrm{H}$. influenzae strains have a variety of mechanisms which can influence its function. Outer membrane proteins such as P2 and P5 facilitate binding of the bacteria to mucus [11,12]. Lipooligosaccharide (a lipopolysaccharide that lacks the $\mathrm{O}$-side chains and is abbreviated as LOS) is present in the cell wall of NTHi strains and has a significant effect on cilial function; Denny described that LOS produced inhibition of ciliary function and loss/death of ciliary mucosal cells [13]. Similar effects on ciliary function have been described from protein $\mathrm{D}$ which is a lipoprotein expressed on the surface of $H$. influenza [14].

\section{Attachment to respiratory mucosa}

A key step in pathogenesis is the ability to adhere to the respiratory mucosa. NTHi appears to have a preference for nonciliated cells or damaged mucosa. There are several specific mechanisms which NTHi strains use to adhere to mucosa.

\section{Adhesins}

The adhesins are a common and important factor to facilitate epithelial attachment. These are present on a large proportion of NTHi strains and share some homology with adhesins expressed by Bordatella pertussis 
[15]. They are also a major target for serum antibodies to NTHi infection [16]. A number of investigators have demonstrated the importance of adhesins and there are 2 main subtypes HMW1 and HMW2 [17].

\section{Pili}

NTHi express pili which are rod-like projections on the surface which cause agglutination of red blood cells and attachment to respiratory tract epithelial cells [18]. There are 5 different types and these pili are present only on a small subset of strains of NTHi [19-21].

\section{Other factors}

Approximately $25 \%$ of NTHi strains lack adhesins/pili but are still able to attach efficiently to respiratory epthilium. Two other factors that are important are the Hia and Hap proteins [22].

\section{Evasion of mucosal immunity}

After attachment to the mucosal surface, strains of NTHi have a variety of different mechanisms which enhance persistence at the epithelial surface.

\section{Proteases}

Immunoglobulin (Ig) A is the main antibody subclass that prevents epithelial infection. IgA binds to bacteria and prevents mucosal attachment, inactivates toxins and facilitates cytotoxicity. The predominant IgA subclass is IgA1. NTHi secretes endopeptidases (Types 1 and 2), which cleave and neutralize IgA1 [23,24]. Nearly all NTHi strains express one of these IgA proteases which are highly effective in inhibiting IgA.

\section{Microcolony formation}

St Geme et al have demonstrated the ability of NTHi to form microcolonies on mucosal surfaces [8]. This property is likely to inhibit the function of secreted bacteriostatic products such as lactoferrrin and lysozymes and also potentially antibody function.

\section{Phase variation/antigenic drift}

Viruses such as influenza have well-documented abilities to frequently change cell structures and this is a key feature in their pathogenesis. H. influenzae is also able to lose or gain cell structures; a property called phase variation. Structures in which this occurs include LOS, adhesins and pili. This ability has significant implications for the function of antibodies and C-reactive protein [25].

In addition to phase variation, some strains of $\mathrm{H}$. influenzae undergo antigenic drift which involves permanent change in amino acid sequences in some important immune structures/epitopes. This is best described in the context of the outer membrane protein P2 (which is strongly immunogenic) [26]. Other examples of antigenic drift involve P5 outer membrane protein and IgA1 proteases.

\section{Intracellular survival/invasion of local tissue}

A potentially very important pathogenic feature of Haemophilus influenzae is its ability to invade local tissue and survive intracellularly in the respiratory tract. This has been described in the context of nontypeable strains. The main cells targeted by NTHi appear to be macrophages and epithelial cells. There have been a number of studies which have demonstrated the in-vitro ability of NTHi to survive inside these cells for at least 72 hours [27-30]. An example of NTHi inside macrophages is shown in Figure 2.

Two early studies demonstrated the presence of NTHi between the epithelial cells of patients with chronic bronchitis and adenoidal inflammation [30,31]. Electron microscopy showed the disruption of intracellular junctions and the presence of bacteria between cells and in the phagocytic vacuoles of mononuclear cells. Forsgren et al demonstrated the presence of viable NTHi in mononuclear and epithelial cells obtained from children who had adenoid tissue resected as part of standard treatment [32].

Moller et al demonstrated extensive invasion of lung explants from patients with end-stage lung disease (including COPD and cystic fibrosis) with $H$. influenza; the organism was present in the epithelium, the submucosa of the bronchi, the bronchioles, the interstitium, and the alveolar epithelium in over half of the subjects

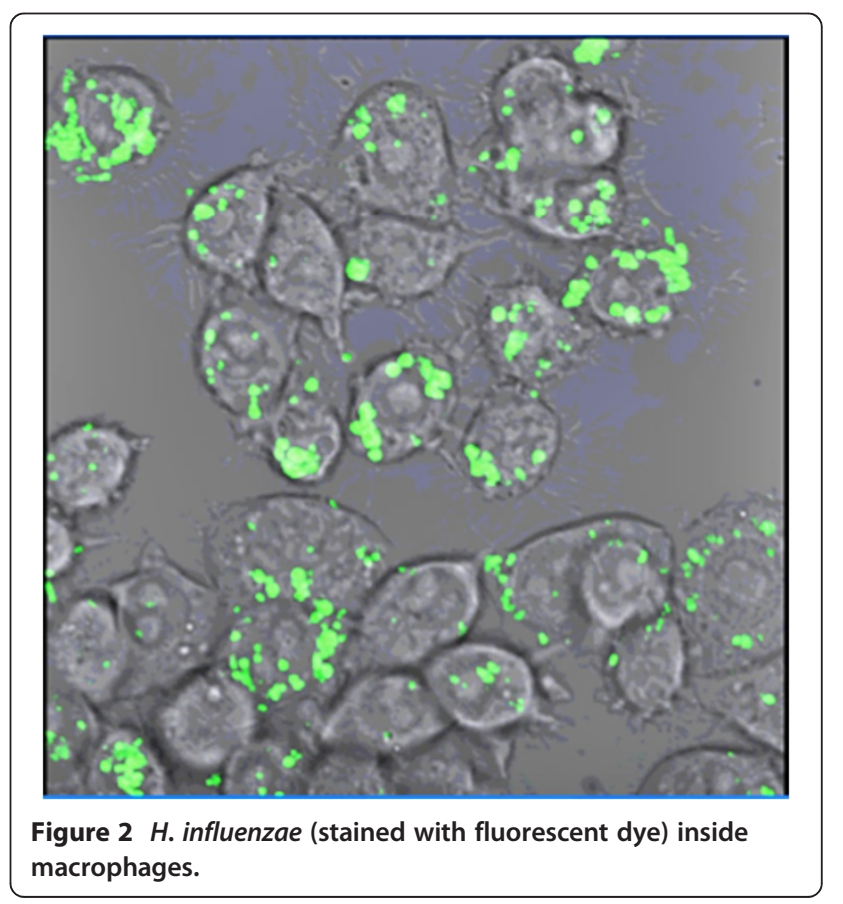


[33]. Dromann et al have demonstrated the presence of $H$. influenzae in lung tissue in $40 \%$ of subjects in all stages of COPD [34]. Another study found very high levels of intracellular NTHi present in subjects who had had exacerbations of COPD [35].

Haemophilus influenzae has a number of mechanisms that allow it to persist in the human host. The ability to be able to invade into lung tissue may be particularly important in the pathogenesis of this bacterium. Key mechanisms are summarized in Table 1.

\section{Immune response}

NTHi is present in the nasopharynx of most healthy adults but only causes clinical disease in a minority of subjects it infects. Therefore the nature of the respiratory tract immune/inflammatory response may be very important in the pathogenesis of this bacterium. NTHi causes strong stimulation of both innate and adaptive immunity.

\section{Innate immune responses}

Innate immunity serves as the first-line of defense against infection and is comprised of both structural and cellular defenses.

Structural defenses have a number of components including cough, barrier function and the mucociliary apparatus. Impairment of mucocilary function as occurs in cystic fibrosis and immotile cilia syndrome, is associated with lung $H$. influenzae infection.

The cellular innate immune response is a rapidly evolving area. It is mediated by neutrophils and particularly macrophages, which recognize bacterial pathogens by toll-like receptors (TLRs). The outer membrane proteins of $H$. influenzae such as P2 and P6 strongly activate innate immunity. P6 activates macrophages to produce interleukin (IL) 8 and tumor necrosis factor alpha $($ TNF- $\alpha$ ) [36,37]. P6 is also important for the migration of dendritic cells. NTHi lysate (i.e. killed/inactivated

Table 1 Important pathogenic features of nontypeable Haemophilus influenzae

\begin{tabular}{ll}
\hline Mucociliary interactions & $\begin{array}{l}\text { Binding to mucus } \\
\text { Inhibition of ciliary function/death } \\
\text { of ciliary cells }\end{array}$ \\
$\begin{array}{l}\text { Attachment to respiratory } \\
\text { mucosa }\end{array}$ & Pdhesins \\
& Hia/Hap proteins \\
Evasion of mucosal & IgA proteases \\
immunity & Microcolony formation \\
& Phase variation/antigenic drift \\
Intracellular survival/invasion & Survival inside mononuclear \\
of local tissue & phagocytes and epithelial cells \\
& Extensive invasion of lung parenchyma
\end{tabular}

bacteria) upregulates the production of nuclear transcription factor-kappa $\beta$ (NF-k $\beta$ ), which is a key driver of inflammation [38]. Epidermal growth factor receptor (EGFR) has also recently been shown to be important in NF- $\kappa \beta$ activation [39].

The NF- $\kappa \beta$ pathway is principally activated through toll-like receptors (TLRs) which function as pattern receptors (e.g. for bacterial motifs). Activation of TLRs by bacterial motifs drives an inflammatory response, which is designed to clear infection. Both TLR-2 and TLR-4 have been shown to be important in immune responses to NTHi $[40,41]$.

TLR-4 primarily recognizes lipopolysaccharide (LPS) a component of the gram-negative cell wall. NTHi has lipooligosaccharide (LOS), which is very similar to LPS but lacks O-antigen units. Activation of TLR4 results in the production of a variety of inflammatory mediators by the macrophage, which have a key role in initiating innate immunity.

TLR-2 is also expressed on the surface of innate and immune cells. Outer membrane P6 activates TLR-2 with up-regulation of NF- $\kappa \beta$ and the production of inflammatory mediators.

\section{Adaptive immune responses}

The adaptive immune response develops after the innate response and is particularly important in chronic infectious disease. It is primarily mediated by B lymphocytes (humoral immunity) and $\mathrm{T}$ lymphocytes (cellular immunity).

Studies have demonstrated that the great majority of healthy subjects and those with chronic airways disease have strong antibody responses to NTHi. It has also been shown that complement is bactericidal for NTHi. Antibody causes activation of the terminal attack complex of complement and this is very effective in killing NTHi [42]. This mechanism may explain why NTHi is primarily a mucosal pathogen that rarely spreads beyond the respiratory tract in contrast to the typeable forms such as Hib which are protected by the tough polysaccharide capsule and frequently cause systemic disease. Hypogammaglobulinaemia has been shown to be an important risk factor for systemic infection with NTHi.

$\mathrm{T}$ cells have a key role in the protection against intracellular infection. Both $\mathrm{T}$ helper (Th) cells and cytotoxic $\mathrm{T}$ (CTL) cells secrete cytokines (which drive inflammation) and produce cytotoxic mediators. The ability of $\mathrm{T}$ cells to proliferate to NTHi stimulation influences clinical disease. Patients with obstructive airways disease have deficient T-cell responses to NTHi when compared to healthy controls specifically; 1 ), decreased Th1 cell function, particularly production of interferon gamma (IFN- $\gamma$ ) \& CD40 ligand (CD40L) [43] and 2), decreased CTL cell function, particularly production of IFN- $\gamma$ [44]. 
In addition macrophage killing of NTHi is enhanced by the addition of IFN- $\gamma$ \& CD40L [45]. A recent study has confirmed that Th1 cell responses to NTHi in COPD are deficient [46] and TLRs appear to be important in this mechanism.

There are two other important situations, which have potentially significant effects on the immune response to NTHi in the lung. They are cigarette smoke and viral infections. These will now be discussed in more detail.

\section{Effect of cigarette smoking on the lung immune response} Cigarette smoking is the key risk factor for the development of COPD and has a significant effect on the lung immune response [47]. Smoking directly damages the respiratory epithelium and inhibits mucociliary function $[48,49]$. It has a wide variety of effects on alveolar macrophages, dendritic cells and lymphocytes which inhibit the ability of the lung to clear infection [47]. Smoking has been found to be associated with increased lung inflammation following challenge with NTHi [50].

\section{Interaction between viral infection and Haemophilus influenzae}

In clinical practice there is a frequent association between viral infection and bacterial infection. In the context of $H$. influenzae infection the two best-described associations have been with 1), epidemic influenza and 2), rhinovirus.

Exacerbations of COPD are frequently associated with combined viral and bacterial infection and the most common co-infection is the combination of rhinovirus and $H$. influenzae, which is also associated with increased severity of exacerbations [51,52]. There is preliminary evidence from laboratory studies that rhinovirus may interact with NTHi. Rhinovirus suppresses host macrophage interleukin 1 responses to NTHi [53] and enhances migration of NTHi across epithelial cells [54].

A major cause of death in epidemic viral influenza is secondary bacterial lung infection. Outbreaks are associated with different bacterial infections. The "Spanish flu" outbreak following World War 1 was associated with a high incidence of $H$. influenzae infection $[55,56]$. Viral influenza causes significant damage to the respiratory epithelial barrier and this may be an important mechanism of secondary bacterial infection.

\section{Clinical features}

Infection of the lower respiratory is predominantly by the nontypeable strains of Haemophilus influenzae (NTHi). The dominant manifestation is bronchitis, which may be acute or chronic and has been well described in the context of COPD, bronchiectasis and cystic fibrosis. Exacerbations are an important feature of these forms of bronchitis and are characterized by episodes of acute clinical deterioration usually in association with increased airway inflammation. Additionally this bacterium is also a major cause of pneumonia.

\section{Chronic obstructive pulmonary disease}

COPD is a major health problem and the fourth leading cause of mortality worldwide. It is characterized by the presence of airway inflammation that is most pronounced in the bronchial wall. This bronchial wall inflammation persists despite the cessation of smoking.

The most common cause of chronic bacterial airway colonization in patients with COPD is NTHi accounting for up to half of all isolates [35,57-60]. The major bacterial cause of exacerbations of COPD is NTHi, 25 to over $80 \%$ of exacerbations are associated with $H$. influenzae [35,57-59]. In addition the bacterial load of NTHi in lung airways has been shown to contribute to airway inflammation in stable chronic bronchitis [61]. Colonization with NTHi is associated with more severe COPD exacerbations [62].

Exacerbations of COPD from NTHi can arise from the acquisition of new strains [9] (presumably from the upper airway) or from existing colonizing strains.

The exact role of NTHi in the inflammatory process is still not well defined but it is possible that NTHi may invade into the bronchial wall to activate $\mathrm{T}$ cells and contribute to inflammation. A murine model of COPD has recently demonstrated that the addition of an NTHi lysate induces the formation of lymphoid follicles in the bronchi [63].

\section{Bronchiectasis and cystic fibrosis}

Bronchiectasis is characterized by persistent bacterial infection that causes lung damage and also results in chronic airflow obstruction [64]. The bacterial infection generally appears to result as a consequence of a defect in host defense which results in chronic bacterial airway infection. The dominant bacterium in bronchiectasis is NTHi and this is a major driver of lung inflammation. There is considerable overlap between bronchiectasis and COPD.

The principal manifestation of cystic fibrosis (CF) is severe and progressive bronchiectasis, which results in respiratory failure. It is thought that a defect in mucociliary function (through the cystic fibrosis transmembrane conductance regulator (CFTR) gene) results in progressive airway infection. NTHi is prominent in the early stages of CF; in later stages other bacterium such as Pseudomonas are predominant. However Moller et al described $H$. influenzae to be the dominant bacterium in the lung parenchyma of explants from CF patients. Therefore in the later stages of CF NTHi may still be important in parenchymal lung infection. 


\section{Pneumonia}

NTHi is also one of the leading causes of pneumonia in adults (with Streptococcus pneumoniae and Moxarella catarrhalis). Most patients with NTHi pneumonia have bronchopneumonia with cough, fever and systemic upset. The illness is generally less fulminant than that with S. pneumoniae and commonly occurs in patients with underlying lung disease (particularly COPD).

Two examples of patients with $H$. influenzae infection are shown in Figures 3 and 4.

\section{Possible role of NTHi in lung cancer}

Smoking is the primary risk factor for both chronic obstructive pulmonary disease (COPD) and lung cancer. Only a minority of smokers develop COPD and the presence of COPD has been demonstrated to be an important risk factor (independent of the risk of smoking) in the development of lung cancer. It has been speculated that NTHi-driven inflammation in the context of COPD may be a risk factor for the development of lung cancer [65].

There have been several mechanisms described which may suggest a role for NTHi-driven inflammation as a risk factor for lung cancer. NTHi activates proliferative and antiapoptotic pathways [38,66] and promotes lung cancer in a Clara cell-targeted mouse model of lung cancer [67]. Interleukin-6 and Il-17 generated in response to NTHi may be important risk factors as well.

\section{Treatment}

Treatment of Haemophilus influenzae infection should be straightforward as this bacterium is usually sensitive to most standard antibiotics. In practice though treatment is

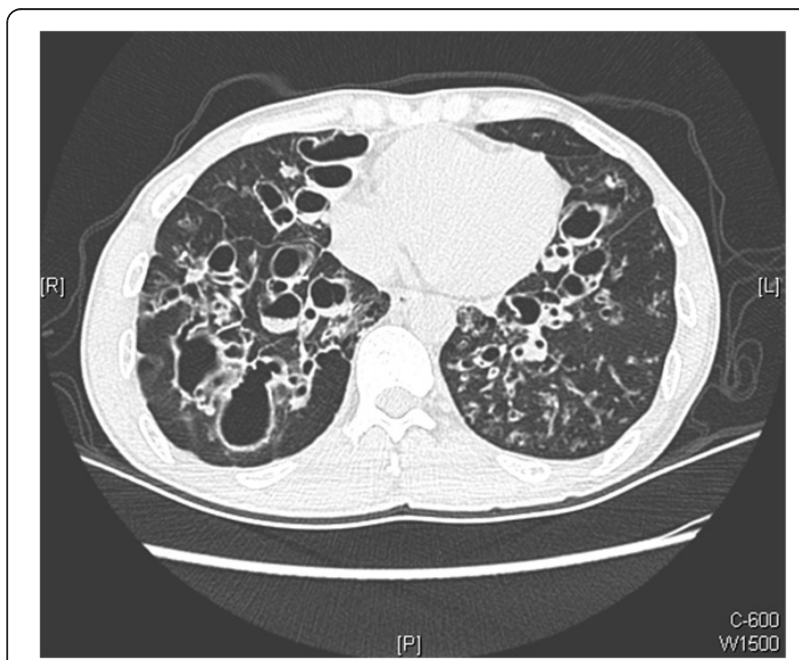

Figure 3 Computed tomography (CT) scan of a subject with severe lower lobe bronchiectasis and recurrent isolation of $H$. influenzae from sputum.

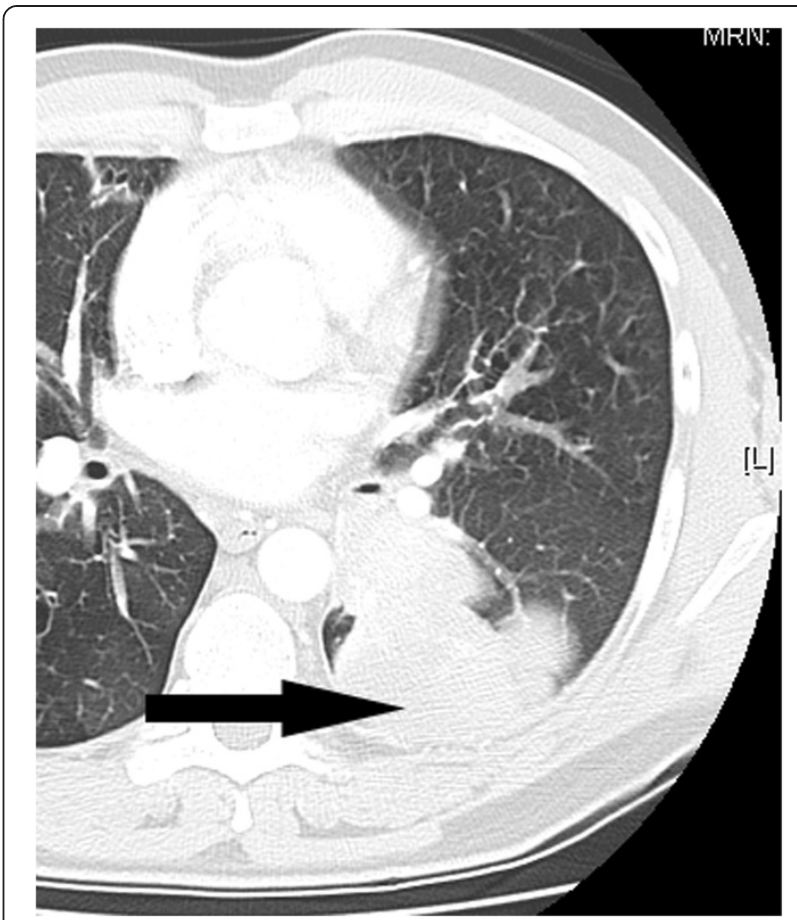

Figure 4 Computed tomography scan taken of a patient with a lung abscess that required surgical removal. $H$. influenzae was isolated from the lung tissue.

often only partially successful with recurrent/nonclearing infection. Particularly in the context of chronic bronchitis (e.g. as in COPD and bronchiectasis) NTHi often appears to have established a niche in the airway, which makes it relatively resistant to chemotherapy.

\section{Use of antibiotics}

Oral antibiotics such as $\beta$-lactams are appropriate firstline therapy for most patients. A proportion of $H$. influenzae isolates produce $\beta$-lactamase (this varies markedly between different locations) and in this circumstance, extended spectrum cephalosporins, amoxicillin-clavulinic acid, trimethoprim-sulfamethoxazole, tetracyclines, quinolones and macrolide antibiotics are appropriate therapeutic choices. In Spain and Japan, $\beta$-lactamase negative, ampicillin-resistant (BLNAR) strains are prevalent. These BLNAR strains are associated with a high incidence of pneumonia $[68,69]$. For hospitalized patients particularly if there is associated respiratory failure the parenteral route of administration may be preferred.

For patients who have repeated isolation of $H$. influenzae despite the use of appropriate antibiotics consideration should be given to the use of longer-term antibiotics or those with good intracellular penetration. As discussed previously NTHi has the ability to live intracellularly and thus be protected from a number antibiotics particularly the $\beta$-lactams [70]. Agents with good 
intracellular penetration include macrolides, tetracyclines and quinolones. In the author's experience, longer courses of antibiotics with good intracellular penetration may be helpful (although this has potential issues of resistance).

\section{Vaccination}

The vaccine to type $\mathrm{B}$ encapsulated $H$. influenzae induces humoral immunity to the capsule and has been highly effective in reducing the incidence of disease from this pathogen. This vaccine is now standard for children

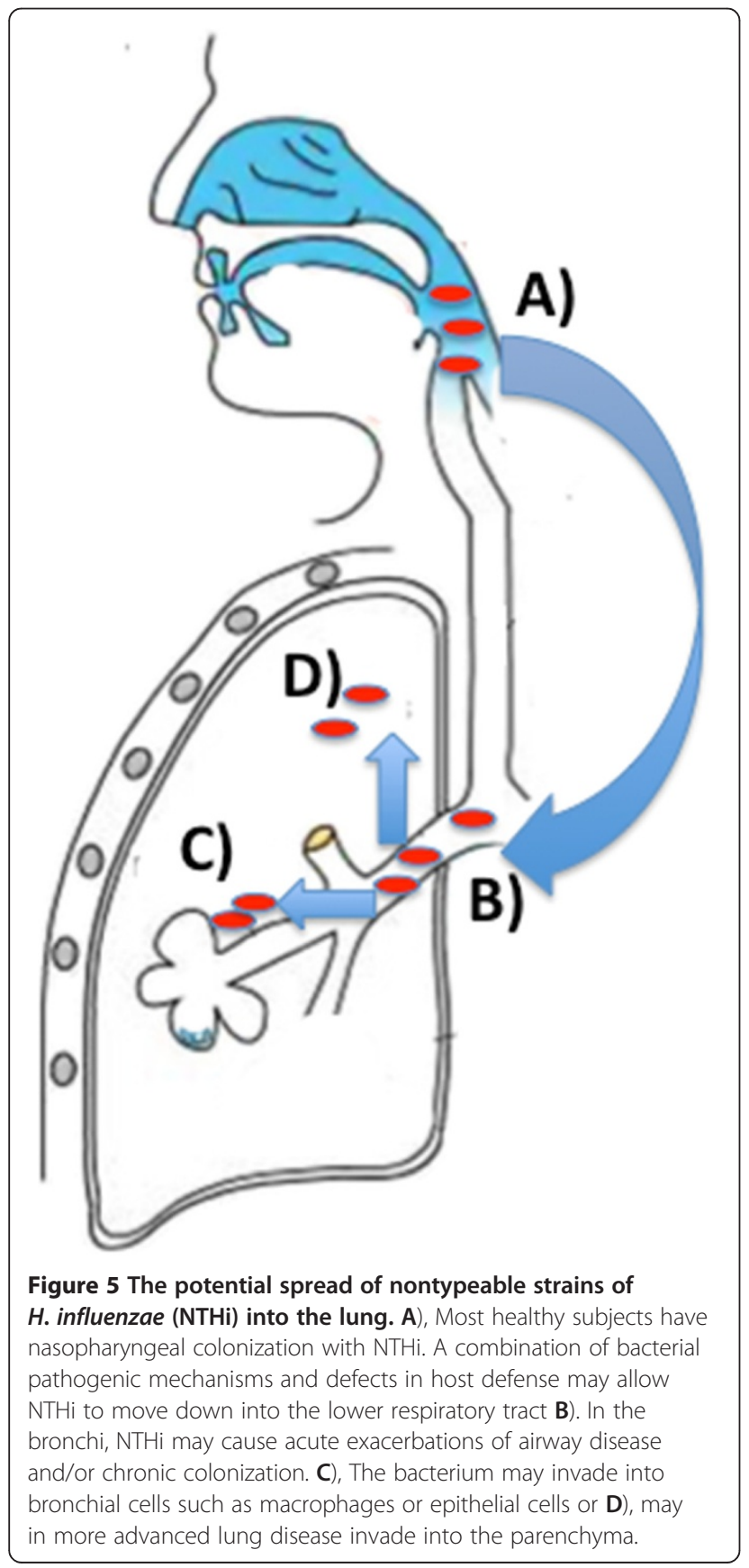

in industrialized countries. Vaccination is usually given at 2 months, 6 months and $12-15$ months.

In contrast to Hib vaccination for NTHi strains is not well established. NTHi infection occurs from a wide variety of different and very heterogeneous strains and the protective immune response has not been clearly defined. There have been a number of published studies measuring the effect of vaccination in animal models. A major problem with the use of animal models is that NTHi is an exclusively human pathogen, which generally does infect animals well.

An oral vaccine consisting of multiple strains of killed NTHi has been used with some reduction in exacerbations [71]. More recently 2 trials of a new form of oral NTHi vaccine have demonstrated a reduction in exacerbations [72,73]. Subjects were given 3 doses of inactivated NTHi on a monthly basis with changes in the expression of $\mathrm{T}$ cell responses and specific immunoglobulin production.

\section{Conclusions}

$H$. influenzae is present in the nasopharynx of most healthy adults. Defects in host defense and pathogenic mechanisms of the bacteria may result in migration into the lower respiratory tract. This results in bronchitis, which may be acute or chronic. Invasion into respiratory tract cells, the bronchial wall and parenchyma of the lung may then occur. This process is summarized in Figure 5.

This bacterium is increasingly being recognized as a major cause of chronic infection/inflammation in the context of COPD. In the author's opinion the establishment of $H$. influenzae infection in the airway may lead to a self-perpetuating inflammatory process that has a major role in the development of airway obstruction. Better understanding of the pathogenesis of Haemophilus influenzae in the respiratory tract is likely to lead to more effective treatment; in particular the use of vaccination.

\section{Competing interests}

The author declares that he has no competing interests.

Received: 19 March 2012 Accepted: 14 June 2012

Published: 14 June 2012

\section{References}

1. Murphy TF: Haemophilus infections. In Harrisons Principles of Internal Medicine. 15 th ed. Edited by Braunwald F, Kaspar Hauser, Longo Jameson. New York: McGraw Hill; 2001:939-942.

2. Moxon ER, Deich RA, Connelly C: Cloning of chromosomal DNA from Haemophilus influenzae. Its use for studying the expression of type $b$ capsule and virulence. J Clin Invest 1984, 73:298-306.

3. Zwahlen A, Kroll JS, Rubin LG, Moxon ER: The molecular basis of pathogenicity in Haemophilus influenzae: comparative virulence of genetically-related capsular transformants and correlation with changes at the capsulation locus cap. Microb Pathog 1989, 7:225-235. 
4. St Geme JW, Takala A, Esko E, Falkow S: Evidence for capsule gene sequences among pharyngeal isolates of nontypeable Haemophilus influenzae. J Infect Dis 1994, 169:337-342.

5. Howard AJ, Dunkin KT, Millar GW: Nasopharyngeal carriage and antibiotic resistance of Haemophilus influenzae in healthy children. Epidemiol Infect 1988, 100:193-203.

6. Samuelson A, Freijd A, Jonasson J, Lindberg AA: Turnover of nonencapsulated Haemophilus influenzae in the nasopharynges of otitis-prone children. J Clin Microbiol 1995, 33:2027-2031.

7. Murphy TF, Sethi S, Klingman KL, Brueggemann AB, Doern GV: Simultaneous respiratory tract colonization by multiple strains of nontypeable haemophilus influenzae in chronic obstructive pulmonary disease: implications for antibiotic therapy. J Infect Dis 1999, 180:404-409.

8. St Geme JW 3rd: The pathogenesis of nontypable Haemophilus influenzae otitis media. Vaccine 2000, 19(Suppl 1):S41-S50.

9. Sethi S, Evans N, Grant BJ, Murphy TF: New strains of bacteria and exacerbations of chronic obstructive pulmonary disease. $N$ Engl J Med 2002, 347:465-471

10. Long SS, Henretig FM, Teter MJ, McGowan KL: Nasopharyngeal flora and acute otitis media. Infect Immun 1983, 41:987-991.

11. Reddy MS, Murphy TF, Faden HS, Bernstein JM: Middle ear mucin glycoprotein: purification and interaction with nontypable Haemophilus influenzae and Moraxella catarrhalis. Otolaryngol Head Neck Surg 1997, 116:175-180.

12. Miyamoto N, Bakaletz LO: Selective adherence of non-typeable Haemophilus influenzae (NTHi) to mucus or epithelial cells in the chinchilla eustachian tube and middle ear. Microb Pathog 1996, 21:343-356.

13. Denny FW: Effect of a toxin produced by Haemophilus influenzae on ciliated respiratory epithelium. J Infect Dis 1974, 129:93-100.

14. Cervin A, Carl n B, Janson $H$, et al: Effects on the ciliated epithelium of protein D-producing and -nonproducing nontypeable Haemophilus influenzae in nasopharyngeal tissue cultures. J Infect Dis 1999, 180:737-746.

15. Barenkamp SJ, Leininger E: Cloning, expression, and DNA sequence analysis of genes encoding nontypeable Haemophilus influenzae high-molecular-weight surface-exposed proteins related to filamentous hemagglutinin of Bordetella pertussis. Infect Immun 1992, 60:1302-1313.

16. Barenkamp SJ, Bodor FF: Development of serum bactericidal activity following nontypable Haemophilus influenzae acute otitis media. Pediatr Infect Dis J 1990, 9:333-339.

17. Falkow S, Barenkamp SJ, St Geme JW 3rd: High-molecular-weight proteins of nontypable Haemophilus influenzae mediate attachment to human epithelial cells. Proc Natl Acad Sci U S A 1993, 90:2875-2879.

18. Krasan GP, Pinkner JS 3rd, St Geme JW, et al: Haemophilus influenzae pili are composite structures assembled via the HifB chaperone. Proc Natl Acad Sci U S A 1996, 93:11913-11918.

19. van Ham SM, van Alphen L, Mooi FR, van Putten JP: The fimbrial gene cluster of Haemophilus influenzae type b. Mol Microbiol 1994, 13:673-684.

20. McCrea KW, Watson WJ, Gilsdorf JR, Marrs CF: Identification of hifD and hifE in the pilus gene cluster of Haemophilus influenzae type b strain Eagan. Infect Immun 1994, 62:4922-4928.

21. Krasan GP, Cutter D, Block SL, St Geme JW 3rd: Adhesin expression in matched nasopharyngeal and middle ear isolates of nontypeable Haemophilus influenzae from children with acute otitis media. Infect Immun 1999, 67:449-454.

22. Barenkamp SJ, St Geme JW 3rd: Identification of a second family of high-molecular-weight adhesion proteins expressed by non-typable Haemophilus influenzae. Mol Microbiol 1996, 19:1215-1223.

23. Mulks MH, Kornfeld SJ, Frangione B, Plaut AG: Relationship between the specificity of IgA proteases and serotypes in Haemophilus influenzae. $J$ Infect Dis 1982, 146:266-274.

24. Plaut AG: The IgA1 proteases of pathogenic bacteria. Annu Rev Microbiol 1983, 37:603-622

25. van Ham SM, van Alphen L, Mooi FR, van Putten JP: Phase variation of $\mathbf{H}$. influenzae fimbriae: transcriptional control of two divergent genes through a variable combined promoter region. Cell 1993, 73:1187-1196.

26. Duim B, Vogel L, Puijk W, et al: Fine mapping of outer membrane protein P2 antigenic sites which vary during persistent infection by Haemophilus influenzae. Infect Immun 1996, 64:4673-4679.
27. Craig JE, Cliffe A, Garnett K, High NJ: Survival of nontypeable Haemophilus influenzae in macrophages. FEMS Microbiol Lett 2001, 203:55-61.

28. Ahren IL, Janson $H$, Forsgren A, Riesbeck K: Protein D expression promotes the adherence and internalization of non- typeable Haemophilus influenzae into human monocytic cells. Microb Pathog 2001, 31:151-158.

29. Ahren IL, Williams DL, Rice PJ, Forsgren A, Riesbeck K: The importance of a beta-glucan receptor in the nonopsonic entry of nontypeable Haemophilus influenzae into human monocytic and epithelial cells. J Infect Dis 2001, 184:150-158.

30. Hers JF, Mulder J: The mucosal epithelium of the respiratory tract in muco-purulent bronchitis caused by Haemophilus influenzae. J Patho Bacteriol 1953, 66:103-108.

31. Farley MM, Stephens DS, Mulks MH, et al: Pathogenesis of IgA1 protease-producing and -nonproducing Haemophilus influenzae in human nasopharyngeal organ cultures. J Infect Dis 1986, 154:752-759.

32. Forsgren J, Samuelson A, Ahlin A, Jonasson J, Rynnel-Dagoo B, Lindberg A: Haemophilus influenzae resides and multiplies intracellularly in human adenoid tissue as demonstrated by in situ hybridization and bacterial viability assay. Infect Immun 1994, 62:673-679.

33. Moller LV, Timens W, van der Bij W, et al: Haemophilus influenzae in lung explants of patients with end-stage pulmonary disease. Am J Respir Crit Care Med 1998, 157:950-956

34. Dromann D, Rupp J, Rohmann K, et al: The TGF-beta-pseudoreceptor $\mathrm{BAMBI}$ is strongly expressed in COPD lungs and regulated by nontypeable Haemophilus influenzae. Respir Res 2010, 11:67.

35. Bandi V, Apicella MA, Mason E, et al: Nontypeable Haemophilus influenzae in the Lower Respiratory Tract of Patients with Chronic Bronchitis. Am J Respir Crit Care Med 2001, 164:2114-2119.

36. Berenson CS, Murphy TF, Wrona CT, Sethi S: Outer membrane protein P6 of nontypeable Haemophilus influenzae is a potent and selective inducer of human macrophage proinflammatory cytokines. Infect Immun 2005, 73:2728-2735.

37. Kurita S, Koyama J, Onizuka S, et al: Dynamics of dendritic cell migration and the subsequent induction of protective immunity in the lung after repeated airway challenges by nontypeable Haemophilus influenzae outer membrane protein. Vaccine 2006, 24:5896-5903.

38. Shuto T, Xu H, Wang B, et al: Activation of NF-kappa B by nontypeable Hemophilus influenzae is mediated by toll-like receptor 2-TAK1-dependent NIK-IKK alpha /beta-I kappa B alpha and MKK3/6-p38 MAP kinase signaling pathways in epithelial cells. Proc Natl Acad Sci U S A 2001, 98:8774-8779.

39. Xu F, Xu Z, Zhang R, et al: Nontypeable Haemophilus influenzae induces COX-2 and PGE2 expression in lung epithelial cells via activation of p38 MAPK and NF-kappa B. Respir Res 2008, 9:16.

40. Wieland CW, Florquin S, Maris NA, et al: The MyD88-dependent, but not the MyD88-independent, pathway of TLR4 signaling is important in clearing nontypeable haemophilus influenzae from the mouse lung. J Immunol 2005, 175:6042-6049.

41. Texereau J, Chiche JD, Taylor W, Choukroun G, Comba B, Mira JP: The importance of Toll-like receptor 2 polymorphisms in severe infections. Clin Infect Dis 2005, 41(Suppl 7):S408-S415.

42. King PT, Ngui J, Gunawardena D, Holmes PW, Farmer MW, Holdsworth SR: Systemic humoral immunity to non-typeable Haemophilus influenzae. Clin Exp Immunol 2008, 153:376-384.

43. King PT, Hutchinson PE, Johnson PD, Holmes PW, Freezer NJ, Holdsworth SR: Adaptive immunity to nontypeable Haemophilus influenzae. Am J Respir Crit Care Med 2003, 167:587-592.

44. King P, Ngui J, Farmer M, Hutchinson P, Holmes P, Holdsworth S: Cytotoxic $T$ cell and natural killer cell responses to nontypeable Haemophilus influenzae. Clin Experi Immunol 2008, 152:542-551.

45. King P, Ngui J, Oppedisano F, Robins-Browne R, Holmes P, Holdsworth S: Effect of interferon gamma and CD40 ligation on intracellular monocyte survival of nontypeable Haemophilus influenzae. APMIS 2008, 116:1043-1049.

46. Knobloch J, Schild K, Jungck D, et al: The T-Helper Cell Type 1 Immune Response to Gram-Negative Bacterial Infections Is Impaired in COPD. Am J Respir Crit Care Med, 183:204-214.

47. Stampfli MR, Anderson GP: How cigarette smoke skews immune responses to promote infection, lung disease and cancer. Nat Rev Immunol 2009, 9:377-384. 
48. Dye JA, Adler KB: Effects of cigarette smoke on epithelial cells of the respiratory tract. Thorax 1994, 49:825-834

49. Jones JG, Minty BD, Lawler P, Hulands G, Crawley JC, Veall N: Increased alveolar epithelial permeability in cigarette smokers. Lancet 1980, 1:66-68.

50. Gaschler GJ, Skrtic M, Zavitz CC, et al: Bacteria challenge in smoke-exposed mice exacerbates inflammation and skews the inflammatory profile. Am J Respir Crit Care Med 2009, 179:666-675.

51. Papi $A$, Bellettato $C M$, Braccioni F, et al: Infections and airway inflammation in chronic obstructive pulmonary disease severe exacerbations. Am J Respir Crit Care Med 2006, 173:1114-1121.

52. Wilkinson TM, Hurst JR, Perera WR, Wilks M, Donaldson GC, Wedzicha JA Effect of interactions between lower airway bacterial and rhinoviral infection in exacerbations of COPD. Chest 2006, 129:317-324.

53. Oliver BG, Lim S, Wark $P$, et al: Rhinovirus exposure impairs immune responses to bacterial products in human alveolar macrophages. Thorax 2008, 63:519-525.

54. Sajjan U, Wang Q, Zhao Y, Gruenert DC, Hershenson MB: Rhinovirus disrupts the barrier function of polarized airway epithelial cells. Am J Respir Crit Care Med 2008, 178:1271-1281.

55. Morens DM, Taubenberger JK, Fauci AS: Predominant role of bacterial pneumonia as a cause of death in pandemic influenza: implications for pandemic influenza preparedness. J Infect Dis 2008, 198:962-970.

56. Brundage JF: Interactions between influenza and bacterial respiratory pathogens: implications for pandemic preparedness. Lancet Infect Dis 2006, 6:303-312

57. Bandi V, Jakubowycz M, Kinyon C, et al: Infectious exacerbations of chronic obstructive pulmonary disease associated with respiratory viruses and non-typeable Haemophilus influenzae. FEMS Immunol Med Microbiol 2003, 37:69-75.

58. Rosell A, Monso E, Soler N, et al: Microbiologic determinants of exacerbation in chronic obstructive pulmonary disease. Arch Intern Med 2005, 165:891-897.

59. Groenewegen $\mathrm{KH}$, Wouters EF: Bacterial infections in patients requiring admission for an acute exacerbation of COPD; a 1-year prospective study. Respir Med 2003, 97:770-777.

60. Murphy TF, Brauer AL, Schiffmacher AT, Sethi S: Persistent colonization by Haemophilus influenzae in chronic obstructive pulmonary disease. Am J Respir Crit Care Med 2004, 170:266-272.

61. Hill AT, Campbell EJ, Hill SL, Bayley DL, Stockley RA: Association between airway bacterial load and markers of airway inflammation in patients with stable chronic bronchitis. Am J Med 2000, 109:288-295.

62. Patel IS, Seemungal TA, Wilks M, Lloyd-Owen SJ, Donaldson GC Wedzicha JA: Relationship between bacterial colonisation and the frequency, character, and severity of COPD exacerbations. Thorax 2002, 57:759-764

63. Moghaddam SJ, Clement CG, De la Garza MM, et al: Haemophilus influenzae lysate induces aspects of the chronic obstructive pulmonary disease phenotype. Am J Respir Cell Mol Biol 2008, 38:629-638.

64. King PT, Holdsworth SR, Freezer NJ, Villanueva E, Gallagher M, Holmes PW: Outcome in Adult Bronchiectasis. Journal of Chronic Obstructive Pulmonary Disease 2005, In Press.

65. Moghaddam SJ, Ochoa CE, Sethi S, Dickey BF: Nontypeable Haemophilus influenzae in chronic obstructive pulmonary disease and lung cancer. Int J Chron Obstruct Pulmon Dis 2011, 6:113-123.

66. Wang B, Lim DJ, Han J, Kim YS, Basbaum CB, Li JD: Novel cytoplasmic proteins of nontypeable Haemophilus influenzae up-regulate human MUC5AC mucin transcription via a positive p38 mitogen-activated protein kinase pathway and a negative phosphoinositide 3-kinase-Akt pathway. J Biol Chem 2002, 277:949-957.

67. Moghaddam SJ, Li H, Cho SN, et al: Promotion of lung carcinogenesis by chronic obstructive pulmonary disease-like airway inflammation in a K-ras-induced mouse model. Am J Respir Cell Mol Biol 2009, 40:443-453.

68. Hasegawa K, Kobayashi R, Takada E, et al: High prevalence of type b beta-lactamase-non-producing ampicillin-resistant Haemophilus influenzae in meningitis: the situation in Japan where Hib vaccine has not been introduced. J Antimicrob Chemother 2006, 57:1077-1082.

69. Garcia-Cobos S, Campos J, Lazaro E, et al: Ampicillin-resistant non-beta-lactamase-producing Haemophilus influenzae in Spain: recent emergence of clonal isolates with increased resistance to cefotaxime and cefixime. Antimicrob Agents Chemother 2007, 51:2564-2573.
70. Ahren IL, Karlsson E, Forsgren A, Riesbeck K: Comparison of the antibacterial activities of ampicillin, ciprofloxacin, clarithromycin, telithromycin and quinupristin/dalfopristin against intracellular non-typeable Haemophilus influenzae. J Antimicrob Chemother 2002, 50:903-906

71. Arandjus C, Black PN, Poole PJ, Wood Baker R, Steurer-Stey C: Oral bacterial vaccines for the prevention of acute exacerbations in chronic obstructive pulmonary disease and chronic bronchitis. Respir Med 2006, 100:1671-1681.

72. Tandon MK, Phillips M, Waterer G, Dunkley M, Comans P, Clancy R: Oral immunotherapy with inactivated nontypeable Haemophilus influenzae reduces severity of acute exacerbations in severe COPD. Chest 2010, 137:805-811.

73. Clancy RL, Dunkley ML: Oral non-typable Haemophilus influenzae enhances physiological mechanism of airways protection. Clin Exp Immunol 2010, 161:127-133.

doi:10.1186/2001-1326-1-10

Cite this article as: King: Haemophilus influenzae and the lung

(Haemophilus and the lung). Clinical and Translational Medicine 2012 1:10.

\section{Submit your manuscript to a SpringerOpen ${ }^{\odot}$ journal and benefit from:}

- Convenient online submission

- Rigorous peer review

- Immediate publication on acceptance

- Open access: articles freely available online

- High visibility within the field

- Retaining the copyright to your article

Submit your next manuscript at $>$ springeropen.com 